\title{
Insalubridade ambiental e aspectos sociais associados a patógenos intestinais isolados de dípteros
}

\section{Unhealthy environment and social aspects associated with intestinal pathogens isolated of dipteral}

\author{
Maria José Rocha Ribeiro \\ Bióloga pela Universidade Estadual de Feira de Santana (UEFS). Mestre em Engenharia Civil e Ambiental pela UEFS
}

\section{Sandra Maria Furiam Dias}

Engenheira Civil. Professora Adjunta do Departamento de Tecnologia da UEFS. Mestre em Recursos Hídricos e Saneamento Ambiental pela Universidade Federal do Rio Grande do Sul (UFRGS). Doutora em Saúde Pública pela Universidade de São Paulo (USP)

\section{Elisa Teshima}

Engenheira de Alimentos. Professora Adjunta do Departamento de Tecnologia da UEFS. Mestre em Ciência e Tecnologia de Alimentos pela Universidade Federal de Viçosa (UFV). Doutora em Ciência e Tecnologia de Alimentos pela UFV

\section{André Renê Barboni}

Engenheiro Elétrico. Biólogo. Professor Titular do Departamento de Saúde da UEFS. Mestre em Engenharia Elétrica pela Universidade de Brasillia (UNB). Doutor em Saúde Pública pela USP

\section{Resumo}

\begin{abstract}
A área do entorno do aterro sanitário do município de Feira de Santana, na Bahia, em 2007, foi avaliada por meio do diagnóstico das condições sanitárias, ambientais, sociais e a suscetibilidade dos moradores com a presença de patógenos intestinais isolados de dípteros. Trata-se de um estudo epidemiológico de abordagem quali-quantitativa, do tipo ecológico, transversal, de comparação espacial e tendência temporal. Foram isolados, dos 10.987 dípteros coletados, Salmonella spp., Escherichia coli, protozoários e helmintos. As condições sanitárias e ambientais verificadas na área são determinantes para os dípteros agirem como vetores urbanos de micro-organismos patogênicos, por meio de contaminação cruzada, como também a falta de alguns serviços básicos de saneamento e as atitudes errôneas da população mantêm microambientes que favorecem o ciclo biológico destes insetos, independentemente do aterro.
\end{abstract}

Palavras-chave: saneamento ambiental; saúde pública; insetos sinantrópicos; enterobactérias.

\begin{abstract}
The area around the landfill of Feira de Santana municipality, in Bahia, in 2007, was assessed by the diagnosis of health sanitary, environmental, and social conditions, and the residents' susceptibility with the presence of intestinal pathogens isolated from flies. This is an epidemiological study of qualitative and quantitative approach of ecological and cross-sectional type, of space comparison, and time tendency. From the 10,987 flies collected, Salmonella sp., Escherichia coli, protozoa and helminths were isolated. The sanitary and environmental conditions found in the area are determinative for flies to act as urban vectors of pathogens through cross-contamination, but also the lack of some basic sanitation services and wrong attitudes of the population keep microenvironments that favor the biological cycle of these insects, regardless the landfill.
\end{abstract}

Keywords: environmental sanitation; public health; synanthropic insects; enterobacteria. 


\section{Introdução}

As ações sanitárias integrantes do saneamento ambiental e aquelas de cunho socioeconômico visam alcançar a salubridade ambiental desejável, que proporciona o controle de doenças transmissíveis, com a finalidade de assegurar condições de saúde aos indivíduos residentes nas zonas urbana e rural. Isso se agrava uma vez que a ocupação de áreas urbanas, no Brasil, apresenta contrates, como uma parcela significativa da população é carente de serviços de saneamento básico e estrutura mínima para uma vida saudável (NASCIMENTO, 2004).

Para alcançá-la, destaca-se como componente indispensável dos serviços básicos de saneamento o gerenciamento de resíduos sólidos que se tornou nas últimas décadas uma preocupação, devido ao aumento da população, ao crescente consumo de materiais descartáveis e não-recicláveis, ao problema de esgotamento dos aterros sanitários e à poluição gerada pela disposição final inadequada dos resíduos sólidos.

Os aterros projetados e operados indevidamente produzem efeitos adversos ao ambiente e danos, principalmente à população circunvizinha, como por exemplo, o escoamento do lixiviado, mau cheiro, atração de roedores e insetos vetores de doenças. Estes ambientes, que são naturalmente contaminados com inúmeros patógenos, servem como criadouros ou locais de visitação de moscas e outros animais, favorecendo a disseminação das bactérias patogênicas e a consequente ocorrência de doenças (HOBBS; ROBERTS, 1999), principalmente, por vias indiretas, pela conexão entre resíduos sólidos, vetores e indivíduos.

Insetos voadores como as moscas, em especial, a Musca domestica, e as espécies pertencentes às famílias Calliphoridae, Sarcophagidae, principalmente, estão associados na disseminação de patógenos, transportando-os por meio mecânico (patas, asas, abdômen, antenas), material regurgitado ou nas fezes. Essa associação é potencializada devido à capacidade das moscas em percorrer longas distâncias (entre 10 a 15 km em 24 horas) (PILEGGI et al, 2003; BRASIL, 2006), serem de interesse médico-sanitário e pelo alto grau de sinantropia, possibilitando incriminá-los como vetores potenciais de bactérias e parasitas em áreas próximas às de disposição final de resíduos sólidos e no ambiente domiciliar (ROITMAN; TRAVASSOS; AZEVEDO, 1987). Outro fator biológico relacionado às moscas é o elevado poder reprodutivo, mantendo uma população durante todo o ano.

A mosca comum (Musca domestica) pode transportar agentes infecciosos para o homem e para outros animais, como: Escherichia coli (DE JESÚs et al, 2004), Escherichia coli O157: H7 (ALAM; ZUREK, 2004; AHMAD; NAGARAJAB; ZUREK, 2007), Salmonella (HOLT et al, 2007), Shigella spp., Aeromonas hydrophila, Vibrio fluvalis, S. flexneri, E. coli - ETEC (ECHEVERRIA et al, 1983), S. fecalis (GELDREICH; KENNER; KABLER, 1964), Enterococcus faecalis, E. faecium e Enterococcus casseliflavus (MACOVEI; ZUREK, 2006), Campylobacter fetus e C. jejuni (ROSEF; KAPPERUD, 1983), Cryptosporidium parvum e Giardia lamblia (SZOSTAKOWSKA et al, 2004), Ascaris suum, Trichuris suis, Strongyloides ransomi, larva e ovos de Metastrongylus sp. (FÖRSTER; KLIMPEL; SIEVERT, 2009).

Muitos destes micro-organismos, especialmente as bactérias da família Enterobacteriaceae (E. coli, Salmonella spp, Shigella spp e Klebsiella spp) (JULSETH et al, 1969), estão envolvidos na decomposição de materiais orgânicos, como também são os principais causadores de enfermidades entéricas ao homem que constantemente ocorrem por meio da contaminação dos alimentos expostos, causando os mais variados sintomas, desde casos agudos até os mais graves, os quais podem levar o indivíduo à morte, assim como geram custos consideráveis no tratamento e na reabilitação para o sistema de saúde do município.

No Estado da Bahia, de acordo com os dados fornecidos pela Segunda Diretoria Regional de Saúde da Secretaria de Saúde do Estado da Bahia, em 2005, foram notificados 4.576 casos de morbidade por diarreia para o município de Feira de Santana (BAHIA, 2005). Estes dados podem não corroborar com a realidade, devido à não-confiabilidade da maioria dos indicadores de morbimortalidade: a subnotificação, tanto no número de internações ou de óbitos, principalmente daqueles menores de um ano e que ficam fora das estatísticas, não retratando a realidade das regiões brasileiras. No entanto, as doenças infecciosas e parasitárias (DIP), no Brasil, são utilizadas para avaliar as condições de desenvolvimento de determinada região, por meio da relação entre níveis de mortalidade e morbidade e condições de vida da população (PAES; SILVA, 1999).

Neste contexto, o artigo tem como objetivo diagnosticar as condições sanitárias, sociais e ambientais, o perfil socioeconômico e a suscetibilidade dos moradores da área do entorno do aterro sanitário do município de Feira de Santana, na Bahia, em 2007, associando-as com a presença de patógenos intestinais isolados de dípteros.

\section{Material e métodos}

O estudo compreendeu duas avaliações: a ocorrência de patógenos em dípteros e o diagnóstico das condições socioambientais com moradores residentes em 156 domicílios, escolhidos aleatoriamente, correspondentes a $25 \%$ das residências existentes em cada subárea (Jacobi, 2006), por meio de entrevistas semiestruturadas e observação de campo sobre as condições sanitárias local e o impacto na saúde dessa população. O questionário constou de 42 perguntas abertas e fechadas, as quais abordam questões multifatoriais sobre os aspectos socioeconômicos, destinação do esgoto doméstico, resíduos sólidos, hábitos e práticas de higiene e condições de saúde da população.

\section{Descrição geral e delimitação da área de investigação}

O estudo compreende a área do aterro sanitário e seu entorno, no município de Feira de Santana, na Bahia. A delimitação da área 
do entorno foi baseada nos dados cartográficos digitais e compreendeu uma faixa de $300 \mathrm{~m}$, medidos de forma radial, a partir do limite territorial do aterro sanitário, em função do que foi determinado pela NBR 13.896 (ABNT, 1997): "os aterros devem possuir uma distância mínima de $500 \mathrm{~m}$ dos núcleos populacionais", como também, o fato do poder de dispersão das moscas e a geografia social peculiar da área. Essa área foi dividida em subáreas para obtenção de setores que apresentassem extensão territorial aproximada à área do aterro sanitário, bem como aglomerassem regiões urbanizadas ou não, resultando em duas subáreas urbanizadas e três subáreas rurais (Figura 1).

A subárea A00 é a área do aterro sanitário de Feira de Santana onde são dispostos os resíduos coletados no município, com a devida infraestrutura para a sua operação: setor da administração do aterro, estacionamento, posto de abastecimento para veículos, oficina e equipamento de autoclavagem.

A subárea A01 fica a oeste do aterro e possui vegetação em fase de regeneração, tendo como grupo predominante as gramíneas e ervas rasteiras e apresenta pequenas manchas de vegetação arbustiva. As edificações se limitam as das fazendas e grandes espaços livres.

A02 corresponde à subárea situada ao norte do aterro de transição entre o urbano e o rural com pouca densidade populacional. A vegetação existente localiza-se em terrenos ainda não-edificados, sendo caracterizada, principalmente, por gramíneas e arbustivos baixos. Foram aplicados 25 questionários aos moradores de 105 residências existentes, sendo que algumas em condições precárias, tais como, construídas de blocos com ou sem reboco, em terrenos à margem de córregos, sujeitos às enchentes e com declividade acentuada, barracos improvisados cobertos de lona e sem piso, localizados em ruas sem pavimentação.

A subárea A03 está situada ao norte e apresenta vegetação com características semelhantes à subárea dois (gramíneas e arbustivos baixas); apresenta 211 residências localizadas em ruas parcialmente pavimentadas e outras sem pavimentação, construídas de tijolo ou bloco, com cobertura de telha tipo cerâmica e algumas de laje, com ou sem reboco, o piso revestido por cimento e muitas não apresentam banheiros, sendo utilizado por famílias meios sanitariamente inadequados, tais como defecar no quintal. Nesta subárea, foram aplicados 52 questionários.

A A04 se situa ao leste, com vegetação constituída de espécies adaptadas ao paisagismo, medianamente urbanizada, nas quais pode ser observado um aglomerado maior de moradias (295 existentes) e 73 famílias entrevistadas. As ruas não são pavimentadas, entretanto, há facilidade de transporte (transporte coletivo). Possui comércio

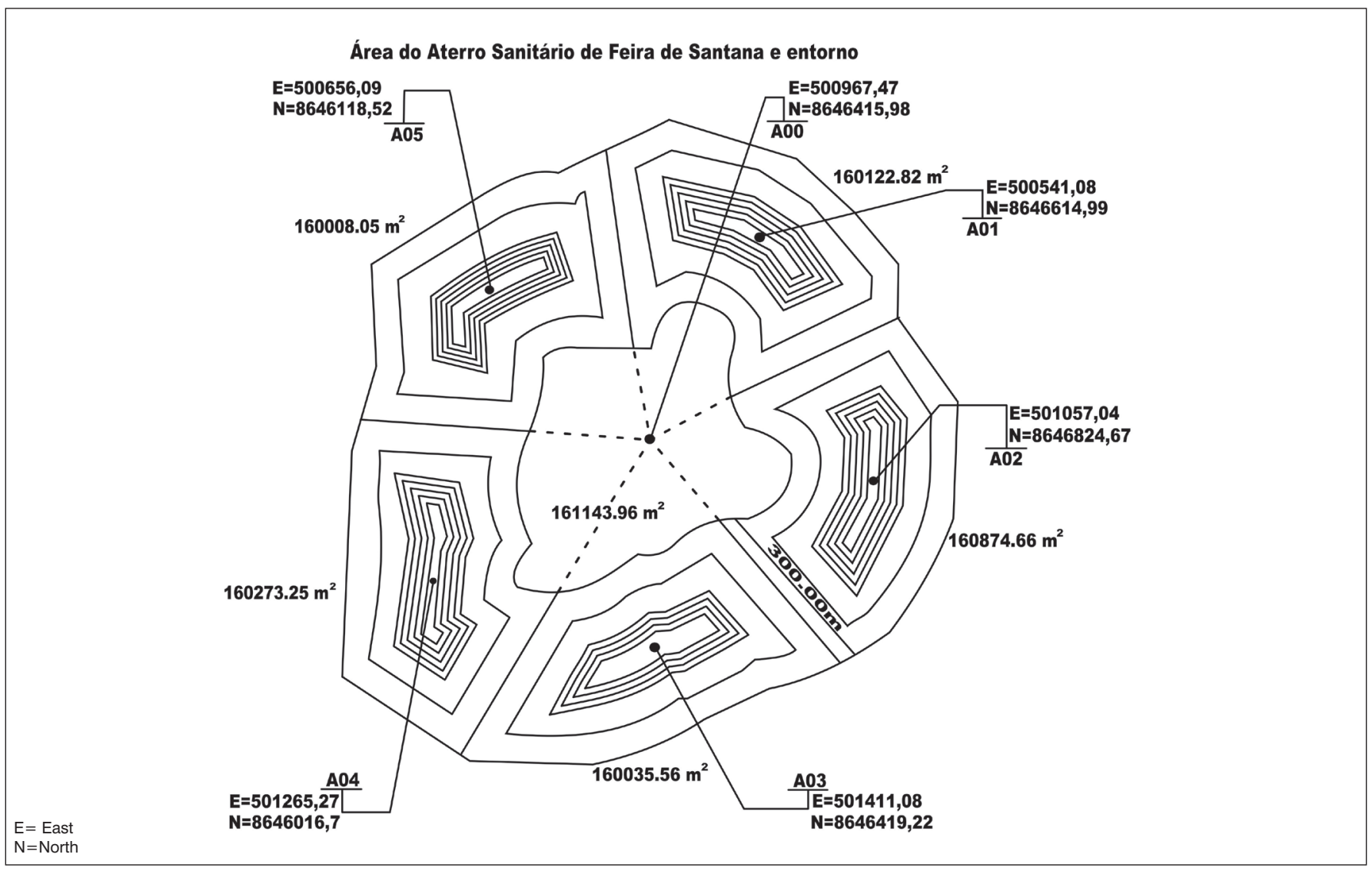

Figura 1 - Desenho esquemático feito a partir de base cartográfica digital em escala original de 1:2.000, fornecida pela Secretária Municipal de Planejamento Ambiental e Arquitetura, da região do aterro sanitário do município de Feira de Santana, com a identificação das subáreas (A00; A01; A02; A03; A04; A05) e suas respectivas coordenadas geográficas. 
caracterizado, principalmente, pela presença de mercearias, mercadinhos e matadouro de animais.

A subárea A05 fica ao sul do aterro, encontra-se bastante antropizada, devido às ações ali desenvolvidas ao longo do tempo (instalação de pequenos sítios, introdução de pomares, cultivo e pastagens com vacas para produção de leite). É ocupada por pequenos sítios que desenvolvem atividades voltadas à agricultura de subsistência, com árvores frutíferas e pequenas culturas de mandioca, feijão e milho. Há, nesta subárea, seis residências à margem de estrada asfaltada, para as quais foram aplicados questionários aos seus moradores.

\section{Coleta das amostras dos dípteros}

As coletas dos dípteros foram realizadas no período de julho a dezembro de 2007, período caracterizado pelo fim de estação chuvosa (inverno) e início de estação seca (verão). Foi instalada uma armadilha para capturar os dípteros (RIBEIRO, 2008), a 1,5 m do solo (GOMES; KOLLER; BARROS, 2000), no centro geométrico de cada subárea de estudo determinada por GPS. No interior das armadilhas, foram colocadas como isca $100 \mathrm{~g}$ de sardinha em estado de putrefação (Pileggi et al, 2003). As armadilhas foram instaladas 24 horas antes das coletas dos dípteros, e as moscas aprisionadas neste período foram transferidas assepticamente para os sacos esterilizados. Em cada área, foram realizadas 12 coletas, em intervalos regulares de 15 dias, perfazendo um total de 72 amostras.

\section{Análise bacteriológica}

As amostras de dípteros provenientes das respectivas estações de captura, contidas nos sacos, foram imobilizadas pelo frio e mortas por asfixia. Em seguida, foram submetidas à técnica de lavado superficial descrita por Pileggi et al (2003), utilizando como diluente a solução salina $\mathrm{NaCl}(0,9 \%)$ esterilizada, na proporção necessária para obtenção da diluição $10^{-1}$ (peso/volume). A partir desta diluição, foram realizadas diluições decimais necessárias, que foram plaqueadas, em duplicatas, na superfície do Agar RAMBACH (MERCK ${ }^{\mathrm{TM}}$ ), um meio de cultura cromogênico diferencial para diagnosticar Escherichia coli e Salmonella spp. (RAMBACH, 1990; GRUENEWALD; HENDERSON; YAPPOW, 1991). Posteriormente, as colônias características de Salmonella spp. e de E. coli foram submetidas às provas bioquímicas e ao teste sorológico, de acordo com a metodologia descrita no APHA, AWWA, WEF (1998).

\section{Análise parasitológica}

Para verificação da presença de helmintos e protozoários, utilizou-se todo o volume da solução salina excedente proveniente da lavagem superficial dos dípteros, após as análises bacteriológicas, segundo o método da sedimentação por centrifugação (NEVES, 2005). Toda solução foi distribuída em tubos e centrifugada a $2.500 \mathrm{rpm}$, por dois minutos, eliminando o sobrenadante e uma gota do sedimento analisado por amostra individual. Realizou-se a leitura em microscópio, com aumentos de 100 e 400 vezes, após lâmina corada com uma gota de lugol. Os parasitos foram identificados e classificados segundo Neves (2005) e Cimerman e Franco (2007). Os espécimes de insetos da ordem díptera foram classificados na categoria sistemática de família, utilizando-se a chave de classificação de McAlpine e McAlpine (1981).

\section{Aspectos éticos}

O projeto foi aprovado pelo Comitê de Ética em Pesquisas da Universidade Estadual de Feira de Santana (UEFS), protocolo 037/2007 (CAAE - 0040.0.059.000-07).

\section{Resultados}

\section{Infraestrutura, hábitos domiciliares e condições socioambientais da população estudada}

Após visita in loco, análise dos mapas e ortofotos e das respostas dos questionários, a área caracteriza-se como típica de conurbação entre o urbano e o rural, dotada de energia elétrica e contemplada pelo abastecimento de água com rede pública de distribuição e, apenas, 1,92\% das residências da subárea A03 consomem também água de poço. A irregularidade do abastecimento ocorre após o horário das 18h00min, apenas na subárea A02, e 60\% dos moradores possuem reservatório superior. Contudo, o hábito de armazenar a água em tonéis (20\%) e reservatórios baixos (20\%) foi constatado em todas as subáreas. Quanto à periodicidade de lavagem dos locais de armazenamento, relatou-se em todas as subáreas: semanalmente (30\%), quinzenalmente (5\%), mensalmente (35\%), duas vezes ao ano (20\%) e uma vez ao ano (10\%).

Em relação aos cuidados com os alimentos, foi constatado que, em média, $88 \%$ dos entrevistados possuem geladeira e em relação ao hábito de lavar as frutas com vinagre (44\%), com detergente (8\%), com água sanitária (4\%), apenas com água (36\%) e 8\% não costumam lavar as frutas antes de ingeri-las. O hábito de lavar as mãos está presente em mais de $80 \%$ das famílias. A frequência da coleta de resíduos sólidos em três dias da semana foi relatada por 96\% dos entrevistados da subárea A02, e 4\% informaram que não há coleta ou não souberam informar.

$\mathrm{Na}$ Tabela 1 estão apresentados os dados sobre as faixas etárias, escolaridade, ocupação, e a renda dos moradores entrevistados nos domicílios das subáreas em estudo.

$\mathrm{Na}$ Tabela 2 estão tabulados os resultados das respostas referentes ao conhecimento dos moradores sobre os dias de coleta, percepção de problemas relacionados ao aterro sanitário e o período em que os entrevistados perceberam a maior presença de moscas nos seus domicílios.

Os moradores (59,62\%) da subárea A03 afirmaram que são afetados por algum problema relacionado ao aterro sanitário de Feira de 
Tabela 1 - Dados sobre as faixas etárias, escolaridade, ocupação e a renda dos moradores das subáreas do entorno do aterro sanitário do município de Feira Santana, Bahia, em 2008

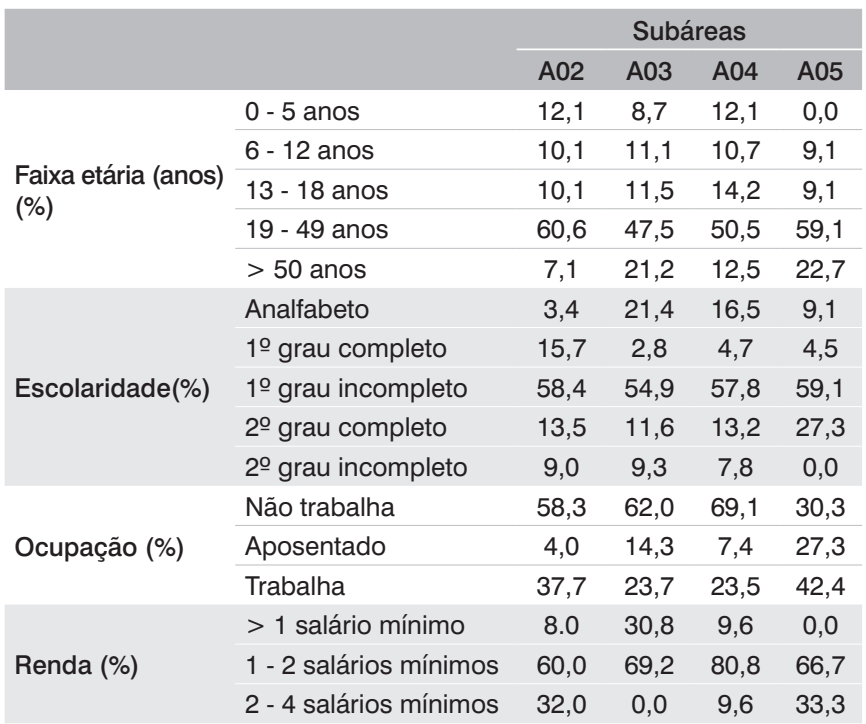

Santana, e a presença de moscas foi a mais citada, conforme dados listados na Tabela 2

Em todas as subáreas, 64\% dos moradores afirmaram não terem conhecimento das doenças causadas pelos resíduos sólidos, enquanto $16 \%$ sabiam que existiam e não informaram, entretanto, $20 \%$ informaram citando algumas delas.

A Tabela 3 demonstra os resultados referentes às condições de destinação do esgoto doméstico, forma de acondicionamento de lixo e os animais mais frequentes encontrados nos domicílios conforme declaração dos moradores das subáreas do entorno do aterro sanitário do município de Feira de Santana, na Bahia, em 2007.

$\mathrm{Na}$ Tabela 4, encontra-se o número de citações referentes aos enteroparasitos relatados e às doenças citadas com mais frequência. Outras doenças como dor de cabeça, alergias, asma, gastrite, gripe, febre, pressão alta, diabetes, osteoporose e viroses foram relatadas.

A existência de casos de diarreia por algum membro da família nas subáreas A03 e A04, durante o último ano foi relatada por $56 \%$ dos entrevistados, enquanto $52 \%$ afirmaram que já houve casos e 48\% afirmaram que não ocorreram casos de diarreia na família.

Com relação às questões de saúde da família, em todas as subáreas, $72 \%$ dos entrevistados afirmaram que algum membro da família realizou exame de fezes, no último ano, enquanto $28 \%$ relataram que não fizeram o referido exame para o mesmo período. Dos que realizaram exames na subárea A02 (16\%), A03 (21,15\%) foram positivos, sendo citados os protozoários e helmintos, apresentados na Tabela 4.

Os moradores das subáreas (100\%) declararam que há presença de animais (cachorros, gatos, galinhas, cavalos, jumentos, entre outros) no peridomicílio e que muitos apresentam algum tipo de doença, assim como foi possível observar in loco um número considerável de pontos de lixo clandestinos.
Tabela 2 - Conhecimento dos moradores sobre os dias de coleta, percepção de problemas relacionados ao aterro sanitário e o período em que perceberam a maior presença de moscas (\%) nas subáreas do entorno do aterro sanitário do município de Feira de Santana, na Bahia, em 2007

\begin{tabular}{|c|c|c|c|c|c|}
\hline \multicolumn{2}{|c|}{ Serviços e percepção dos moradores (\%) } & \multirow{2}{*}{$\begin{array}{c}\text { A02 } \\
37,50\end{array}$} & \multirow{2}{*}{$\begin{array}{c}\text { A03 } \\
63,46\end{array}$} & \multirow{2}{*}{$\begin{array}{c}\mathrm{A} 04 \\
23,29\end{array}$} & \multirow{2}{*}{$\begin{array}{l}\text { A05 } \\
0,00\end{array}$} \\
\hline Conhecimento & $\left(2^{\mathrm{a}}, 4^{\mathrm{a}}\right.$ e $6^{\mathrm{a}}$ feira $)$ & & & & \\
\hline dos moradores & ( $3^{\mathrm{a}}, 5^{\mathrm{a}}$ feira e sábado) & 45,83 & 30,77 & 72,60 & 66,67 \\
\hline $\begin{array}{l}\text { sobre os dias } \\
\text { de coleta }\end{array}$ & Não sabiam informar & 16,67 & 5,77 & 2,74 & 33,33 \\
\hline & Não há coleta & 0,00 & 0,00 & 1,37 & 0,00 \\
\hline \multirow{7}{*}{$\begin{array}{l}\text { Período em que } \\
\text { percebem a } \\
\text { maior presença } \\
\text { de moscas }\end{array}$} & Verão & 20 & 80,77 & 69,86 & 50 \\
\hline & Semana Santa & 16 & 7,69 & 8,22 & 50 \\
\hline & O ano todo & 20 & 3,85 & 6,85 & 0,00 \\
\hline & Outono & 16 & 3,85 & 4,11 & 0,00 \\
\hline & Primavera & 4 & 0,00 & 4,11 & 0,00 \\
\hline & Inverno/dias de chuva & 8 & 1,92 & 2,74 & 0,00 \\
\hline & Não sabiam & 16 & 1,92 & 4,11 & 0,00 \\
\hline \multirow{5}{*}{$\begin{array}{l}\text { Percepção } \\
\text { de problemas } \\
\text { relacionados } \\
\text { com o aterro } \\
\text { sanitário }\end{array}$} & Presença de mosca & 86,7 & 94,23 & 100,0 & 66,6 \\
\hline & Mau cheiro & 69,6 & 51,92 & 98,0 & 100,0 \\
\hline & Fumaça & 32,4 & 7,69 & 46,6 & 33,3 \\
\hline & Poeira & 19,7 & 15,38 & 32,2 & 50,0 \\
\hline & Não sabiam informar & 0,00 & 0,00 & 0,00 & 33,3 \\
\hline
\end{tabular}

\section{Presença de Salmonella spp., Escherichia coli e o número de dípteros capturados no aterro sanitário do município de Feira de Santana e áreas do seu entorno}

Foram capturados 10.987 espécimes de dípteros, e classificadas na categoria sistemática de família Calliphoridae e outros (Sarcophagidae, Muscidae, Tachinidae e outros).

Nos dípteros, foram identificados os protozoários: Entamoeba coli, Entamoeba histolytica e Iodamoeba butschlii e os seguintes helmintos: Trichuris trichiura, Ascaris lumbricoides, Endolimax nana, ovo de ancilostomídeo, Hymenolepis nana, larva de ancilostomídeo, larva de Strongyloides stercoralis, Tricuris sp., e larva de Strangyloides sp., assim como, Salmonella spp. e Escherichia coli em todas as amostras analisadas das seis subáreas, sendo que na subárea A03 ocorreu o maior número de amostras positivas para os patógenos citados.

\section{Discussão}

A relação homem-meio ambiente é complexa e envolve muitos fatores que podem ser estudados isoladamente, apesar de estarem ligados de maneira intrínseca. Muitos desses fatores surgem por meio de uma série de modificações antrópicas constantes, à medida que aumenta o progresso tecnológico, o crescimento demográfico e o desenvolvimento econômico.

Neste estudo, mesmo tendo sido abordado apenas uma parte dos problemas decorrentes desta relação, a investigação realizada permite fazer considerações a partir da insalubridade ambiental e dos aspectos sociais encontrados na região, objeto deste estudo. 
Tabela 3 - Condições sanitárias das subáreas do entorno do aterro sanitário do município de Feira de Santana, na Bahia, em 2007

\begin{tabular}{|c|c|c|c|c|c|c|c|c|c|c|}
\hline \multirow[t]{2}{*}{ Subárea } & \multicolumn{3}{|c|}{ Destino do esgoto sanitário (\%) } & \multicolumn{2}{|c|}{ Acondicionamento do lixo (\%) } & \multicolumn{5}{|c|}{ Declaram a presença de animais no domicílio (\%) } \\
\hline & Fossa $^{1}$ & A céu aberto & Rede pública & Saco & Outros* & Mosca & Baratas & Mosquitos & Ratos & Outros \\
\hline A02 & 80 & 95,96 & 4,04 & 68 & 32 & 100 & 92 & 80 & 56 & $48^{\star \star}$ \\
\hline $\mathrm{A} 03$ & 42,69 & 100 & 0 & 76,9 & 23,1 & 100 & 92,31 & 90,38 & 90,38 & $86,43^{* *}$ \\
\hline A04 & 49,32 & 100 & 0 & 78 & 22 & 100 & 97,26 & 94,52 & 90,41 & $35,62^{* *}$ \\
\hline A05 & 83,33 & 100 & 0 & 66,67 & 33,34 & 100 & 100 & 100 & 100 & $83,33^{* *}$ \\
\hline
\end{tabular}

*Outros: balde, caixas, caixotes, lata de tinta, entre outros; ${ }^{*}$ Outros: caramujo, escorpião, pulga, entre outros; ${ }^{1} \mathrm{~A}$ fossa atende apenas os dejetos provenientes do vaso sanitário.

Tabela 4 - Número de citações referentes aos enteroparasitos relatados e às queixas/doenças mais frequentes (em \%) relacionadas ao saneamento ambiental, reportadas pela população das subáreas do entorno do aterro sanitário da cidade de Feira de Santana na Bahia, em 2007

\begin{tabular}{|c|c|c|c|c|}
\hline Enteroparasitos & $\mathrm{A} 02$ & $\mathrm{~A} 03$ & A04 & A05 \\
\hline Ameba & 2 & 4 & 10 & 0 \\
\hline Lombriga & 2 & 2 & 5 & 0 \\
\hline Verme & 5 & 12 & 4 & 0 \\
\hline Giardia & 1 & 2 & 2 & 0 \\
\hline Entamoeba & 1 & 1 & 2 & 0 \\
\hline Endolimax nana & 1 & 2 & 1 & 0 \\
\hline Entamoeba histolytica & 2 & 5 & 6 & 0 \\
\hline Schistosoma mansoni & 2 & 5 & 6 & 0 \\
\hline \multicolumn{5}{|l|}{ Doenças } \\
\hline Diarreia & 4,0 & 17,3 & 20,5 & 0,0 \\
\hline Dengue & 4,0 & 5,8 & 0,0 & 0,0 \\
\hline Doenças de pele & 4,0 & 5,8 & 0,0 & 0,0 \\
\hline Doenças de Chagas & 0,0 & 1,9 & 0,0 & 0,0 \\
\hline Verminoses & 0,0 & 1,9 & 2,7 & 0,0 \\
\hline S. mansoni & 0,0 & 3,8 & 1,4 & 0,0 \\
\hline
\end{tabular}

Os resultados demonstraram que, nas seis subáreas, houve a ocorrência de dípteros transportando Escherichia coli, Salmonella spp., protozoários e helmintos, visto que podem estar associados aos fatores sociais, condições ambientais e hábitos higiênicos negligenciados por parte dos moradores, conforme dados demonstrados nas Tabelas 1, 2,3 e 4 . A presença do maior número de parasitas intestinais identificados e a quantidade elevada de dípteros capturados, na subárea A03, têm nas rotinas cotidianas dos moradores, como: resíduos sólidos acondicionados em recipientes sem tampas, descarte da água de lavagem de louças próxima ao domicílio, armazenamento de resíduos sólidos nos quintais e peridomicílio papel preponderante, além das práticas higiênicas e baixo nível socioeconômico (Tabela 1). Nessa subárea, verificaram-se muitos animais como porcos, cachorros, galinhas, gatos, cavalos que conviviam e circulavam pelas ruas sem apresentar incômodo aos moradores. No entanto, a presença de fezes de animais são microambientes favoráveis à proliferação de bactérias patogênicas servindo de fonte de contaminação e atração para vetores que transportam esses micro-organismos, como observado nas análises realizadas pelos autores: Monrique-Saide e Delfin-González (1997); Oliveira; Mello e d'Almeida (2002); Pileggi et al (2003), Cárdenas e Martinez (2004), Ribeiro e Barboni (2006) e Oliveira et al (2006).

Avaliando os dados sobre os aspectos socioambientais, observouse na subárea A03 que algumas famílias não possuem banheiros utilizando formas sanitariamente inadequadas, com grandes riscos de contaminação do meio ambiente, como também, a inadequação na forma de armazenamento e manuseio da água (tanques e tonéis) pela população pode explicar fatores de riscos para a infecção por muitas parasitoses (Tabela 2, 3 e 4). A ocorrência destas está associada à ausência de água em quantidade e qualidade adequadas ao consumo humano, de banheiros, fatores sociais (precárias condições de higiene existentes), econômicos e culturais (hábitos inadequados) da população, que em conjunto proporcionam condições favoráveis à sua expansão. Em pesquisa realizada por Heller (1997), a falta de esgotamento sanitário apresentou evidências de que o maior risco para as helmintoses intestinais está associado à deposição dos esgotos no terreno peridomiciliar ou nas ruas.

Mesmo com a coleta de resíduos sólidos, três vezes na semana, a população apresenta atitudes inadequadas quando se observa a deposição de resíduos sólidos próximos das casas, lixeiras abertas e armazenamento em quintais. Estes procedimentos, além de gerar poluição visual, atraem animais (porcos, galinhas) e servem de criadouros para insetos vetores e, consequentemente, trazem riscos à saúde da população.

Segundo Moraes (1998, p. 9), há evidências de "uma associação estatisticamente significante entre o tipo de acondicionamento domiciliar de resíduos sólidos, bem como a coleta dos resíduos sólidos domiciliares no ambiente de domínio público e a prevalência de Ascaris lumbricoides, Trichuris trichiura e ancilostomídeos em crianças entre 5 a 14 anos, e a incidência de diarreia em crianças menores de 5 anos". As doenças relacionadas à falta de saneamento mais citadas pela população do entorno do aterro sanitário de Feira de Santana foram: a diarreia predominantemente nas áreas A03 e A04, locais onde a insalubridade ambiental é mais acentuada (Tabela 2), que, em conjunto com os dados sociais, econômicos e culturais, potencializam essa realidade.

Os moradores, que no momento da aplicação do questionário declararam e apresentaram exames de fezes, foram poucos e conforme os dados apresentados das diferentes subáreas, na Tabela 2, acreditase que quando o morador cita "ameba" e "lombriga", ele se refere à Entamoeba coli e Ascaris lumbricoides, respectivamente. Enquanto que "verme" pode ser entendido como qualquer helminto ou protozoário. O enteroparasito Schistosoma mansoni foi citado, entretanto, não representa nenhuma relação com as condições de insalubridade das subáreas, provavelmente a população adquiriu em outras localidades. Este enteroparasito é encontrado em ambientes de coleções de água 
(margens de rios, lagos, lagoas, riachos, pequenos represamentos), que não foram observadas no bairro.

As infecções causadas pelos parasitos patogênicos constituem processos patológicos no organismo humano ou animal, e estão relacionadas a diversos fatores que concorrem para assegurar este processo com o parasito, o hospedeiro e o meio ambiente. Alguns fatores são: viabilidade dos ovos por muitos meses ou até anos; grande concentração de indivíduos vivendo em condições precárias de saneamento básico; grande número de ovos no peridomicílio; temperatura média anual; umidade ambiental elevada e dispersão dos ovos. Como exemplo, pode-se citar o ovo de Ascaris lumbricoides que pode sobreviver por até quatro anos no ambiente (NEVES, 2005).

Pela associação entre saneamento, vetores e saúde, é importante que sejam realizadas ações preventivas por meio de mudanças estruturais de saneamento, como: manejo adequado de excretas e esgotos, controle de vetores, acondicionamento adequado dos resíduos sólidos nas residências e respeito aos horários de coleta pública dos mesmos. Porém, muitas dessas mudanças dependem da ação governamental e outras, de ampla campanha de educação ambiental.

Lixões e aterros mal operados são considerados locais insalubres, os quais também contribuem para o aumento da população de dípteros. Contudo, inferências sobre a influência e contribuição do aterro sanitário do município de Feira de Santana para os problemas relatados (mau cheiro, fumaça, ratos e aumento no número de insetos) pela população do entorno e pelo aumento do número de dípteros encontrados, neste estudo, não podem ser confirmadas, pois diversos outros fatores nas subáreas, como o acúmulo de resíduos sólidos no peridomicílio, a criação de animais, a presença de valas e o escoamento de esgotos pelas ruas, os hábitos higiênicos pessoais e domésticos, entre outros, podem ter sido relevantes na determinação dos mesmos.

Neste contexto, os resultados encontrados em geral reafirmam que a insalubridade ambiental favorece a atração e o desenvolvimento de diversos vetores, veiculadores de micro-organismos causadores de doenças em humanos e animais, podendo ser identificado que a população estudada é suscetível de ser afetada pelas questões ambientais, comprometendo a qualidade de vida e aumentando os problemas de saúde.

\section{Conclusões}

As condições sanitárias/ambientais avaliadas in loco contribuem para o nível encontrado de bactérias e protozoários e com a endemicidade das moscas, que podem agir como vetores mecânicos, seja no ambiente extra ou intradomiciliar, apresentando risco para a saúde pública e, principalmente, para as crianças.

O risco de contaminação indireta por enteroparasitos é uma realidade: os ovos, as larvas de helmintos e os oocistos de protozoários podem ser disseminados pelo vento, água (chuvas) e pelas moscas, podendo contaminar alimentos sólidos e líquidos e posteriormente ingeridos pelo hospedeiro. As doenças relatadas pelos moradores apresentam uma relação com as condições insalubres do ambiente peridomiciliar.

Não foi possível comprovar a influência do aterro sanitário sobre a presença/número de dípteros coletados, nem sobre a presença de patógenos, uma vez que a ausência de alguns serviços básicos de saneamento (disposição e coleta de esgotos e resíduos sólidos) mantém microambientes favoráveis ao ciclo biológico das moscas e à presença de fatores intervenientes. Vale destacar que aterros sanitários ou controlados, quando bem operados, não expõem matéria orgânica e, consequentemente, podem minimizar a presença destes.

\section{Agradecimentos}

À UEFS, à Prefeitura Municipal de Feira de Santana (BA) e à Coordenação de Aperfeiçoamento de Pessoal de Nível Superior (CAPES).

\section{Referências}

AHMAD, A.; NAGARAJAB, T.G.; ZUREK, L. Transmission of Escherichia coli $\mathrm{O} 157: \mathrm{H} 7$ to cattle by house flies. Elsevier. Preventive Veterinary Medicine, v. 80, n.1, p. 74-81, 2007.

ALAM, M.J.; ZUREK, L. Association of Escherichia coli O157:H7 with Houseflies on a Cattle Farm. Applied and Environmental Microbiology, v. 70, n. 12 , p. $7578-7580,2004$

APHA, AWWA, WEF. Standard methods for the examination of water and wastewater. 20 $0^{\text {th }}$ ed. Washington: American Public Health Association, 1998.

ASSOCIAÇÃO BRASILEIRA DE NORMAS TÉCNICAS (ABNT). NBR 13.896: Aterros de resíduos não perigosos - critérios para projeto, implantação e operação - Procedimento. São Paulo: ABNT, 1997.
BAHIA. Secretaria de Saúde. $2^{a}$ Diretoria Regional de Saúde. Coordenação de Assistência, Vigilância e Proteção a Saúde. Monitoramento de doenças diarréicas agudas - MDDA, Feira de Santana: $2^{\mathrm{a}}$ DIRES, 2005.

BRASIL. Fundação Nacional de Saúde. Manual de saneamento. 3 ed. Brasília: Fundação Nacional de Saúde, 2006.

CÁRDENAS, M.; MARTÍNEZ, R. Protozoários parasitos de importância em saúde pública transportados por Musca domestica Linnaeus em Lima, Perú. Revista Peru Biologia, v. 11, n. 2, p. 149-153, 2004.

CIMERMAN, B.; FRANCO, M.A. Atlas de Parasitologia: Artrópodes, Protozoários e Helmintos. São Paulo: Atheneu, 2007. 
DE JESÚS, A.J.; et al. Quantitative contamination and transfer of Escherichia coli from foods by houseflies, Musca domestica L. (Diptera: Muscidae). Elsevier. International Journal of Food Microbiology; v. 93, n. 3, p. 259-262, 2004.

ECHEVERRIA, P.L.; et al. Flies as a Source of Enteric Pathogens in a Rural Village In Thailand. Applied And Environmental Microbiology, v. 46, n. 1, p. 32-36, 1983.

FÖRSTER, M.A.; KLIMPEL, S.A.; SIEVERT, K. The House Fly (Musca Domestica) as a Potential Vector of Metazoan Parasites Caught in a Pig-Pen in Germany. Elsevier. Veterinary Parasitology, v. 160, n. 1, p. 163-167, 2009.

GELDREICH, E.E.; KENNER, B.A.; KABLER, P.W. Occurrence of Coliforms, Fecal Coliforms, and Streptococci on Vegetation and Insects. Applied Microbiology, v.1, n. 1, p. 63-69, 1964.

GOMES, A.; KOLLER, W.W.; BARROS, A.T.M. Sazonalidade da moscavarejeira, Cochliomyia macellaria (Diptera: Calliphoridae), na região dos cerrados, Campo Grande, MS. Revista Brasileira de Parasitologia Veterinária - Brazilian Journal of Veterinary Parasitology, v. 9, n. 2, p. 125-128, 2000.

GRUENEWALD, R.; HENDERSON, R.W.; YAPPOW, S. Use of Rambach propylene glycol containing agar for identification of Salmonella spp. Journal of Clinical Microbiology, v. 29, n.10, p. 2354-2356, 1991.

HELLER, L. Saneamento e Saúde. Brasília: OPAS/OMS, 1997. 97 p.

HOBBS, B.C.; ROBERTS, D. Toxinfeccões e controle higiênico-sanitário de alimentos. São Paulo: Varela, 1999.

HOLT, P.S.; et al. Isolation Of Salmonella Enterica Serovar Enteritidis from Houseflies (Musca Domestica) Found in Rooms Containing Salmonella Serovar Enteritidis-Challenged Hens. Applied And Environmental Microbiology, v. 73, n. 19, p. 6030-6035, 2007.

JACOBI, P. Cidade e Meio Ambiente: percepções e práticas em São Paulo. 2 ed. São Paulo: Annablume, 2006.

JULSETH, R.M.; et al. Experimental Transmission of Enterobacteriaceae by Insects' - Fate of Salmonella Fed to the Hide Beetle Dermestes Maculatus and a Novel Method for Mounting Insects. Applied Microbiology, v. 17, n. 5, p. 710-713, 1969.

MACOVEI, L.; ZUREK, L. Ecology of Antibiotic Resistance Genes: Characterization of Enterococci from Houseflies Collected in Food Settings. Applied and Environmental Microbiology, v. 72, n. 6, p. 40284035, 2006

MCALPINE, J.F.; MCALPINE, J.F. Morphology and terminology-Adults. In: McAlpine, J.P. et al (Ed.). Manual of Nearctic Díptera, Ottawa: Research Bronch, Agriculture Canada, 1981.

MORAES, L.R.S. Impacto na saúde do acondicionamento e coleta dos resíduos sólidos domiciliares. In: XXVI Congresso Interamericano de Ingeniería Sanitaria y Ambiental, Lima - Peru, Noviembre, p. 2-12, 1998
MONRIQUE-SAIDE, P.C.; DELFIN-GONZÁLEZ, H. Importancia de las moscas como vectores potenciales de enfermedades diarreicas en humanos. Revista Biomédica, v. 8, n. 3, p. 163-170, 1997.

NASCIMENTO, G.A. Saneamento Básico em áreas urbanas pobres: planejamento e gestão de Programas Sul do Brasil. 230f. Tese (Doutorado em Engenharia de Produção) - Universidade Federal de Santa Catarina, Florianópolis, 2004

NEVES, D.P. Parasitologia humana. 11 ed. Rio de Janeiro: Atheneu, 2005.

OLIVEIRA, V.C.; MELLO, R.P.; D'ALMEIDA, J.M. Dípteros muscóides como vetores mecânicos de ovos de helmintos em jardim zoológico, Brasil. Revista de Saúde Pública, v. 36, n. 5, p. 614-620, 2002.

OLIVEIRA, V.C.; et al. Enterobactérias associadas a adultos de Musca domestica (Linnaeus, 1758) (Díptera: Muscidae) e Chrysomya megacephala (Fabricius, 1754) (Diptera: Calliphoridae) no Jardim Zoológico, Rio de Janeiro. Arquivo Brasileiro de Medicina Veterinária e Zootecnia, v. 58, n. 4, 2006, p. 556-561

PAES, N.A.; SILVA, L.A.A. Doenças infecciosas e parasitárias no Brasil: uma década de transição. Revista Panamericana Salud Publica, v. 6, n. 2, p. 99-109, 1999.

PILEGGI, M.; et al. Insetos do Aterro Sanitário de Ponta Grossa, Paraná, como Potenciais Disseminadores de Enterobactérias Patogênos. Ciências Biologia e Saúde, v. 9, n. 1, p. 7-12, 2003.

RAMBACH, A. New plate medium for facilitated differentiation of Salmonella spp.from Proteus spp. And other enteric bacteria. Applied and Environmental Microbiology, v. 56, n. 1, p. 301-303, 1990

RIBEIRO, M.J.R.; BARBONI, S.A.V. Transporte mecânico de enterobactérias por dípteros do Aterro Sanitário de Feira de Santana, Bahia, 2005. In: VIII Encontro de Biologia da UEFS - Feira de Santana: Universidade Estadual de Feira de Santana, v. 1, n. 8, p. 92,2006

RIBEIRO, M.J.R. Associação das condições sanitárias e ambientais com patógenos intestinais isolados de dípteros capturados em área residencial entorno do Aterro Sanitário de Feira de Santana, Bahia, 2007. 104 fls. Dissertação em Engenharia Civil e Ambiental. Universidade Estadual de Feira de Santana. Feira de Santana, Bahia, 2008.

ROITMAN, I.; TRAVASSOS, L.R.; AZEVEDO, J.L. Tratado de Microbiologia. São Paulo: Manole, 1987.

ROSEF, O.; KAPPERUD, G. House Flies (Musca Domestica) as Possible Vectors of Campylobacter Fetus Subsp. Jejuni. Applied and Environmental Microbiology, v. 45, n. 2, p. 381-383, 1983.

SZOSTAKOWSKA, B. et al. Cryptosporidium parvum and Giardia lamblia Recovered from Flies on a Cattle Farm and in a Landfill. Applied and Environmental Microbiology, v. 70, n. 6, p. 3742-3744, 2004 